\title{
Effect of Grain Boundary Formation in Microstructural Changes in IN 738 Service Exposed Turbine Blade
}

\author{
Afolabi Lukmon Owolabi ${ }^{1}$, Puteri Sri Melor Megat-Yusoff ${ }^{1, *}$, Norlaili Amir ${ }^{1}$., M. S. \\ Jasmani $^{2}$ and S.M.A. Syed Ahmad Ghazali ${ }^{3}$ \\ ${ }^{1}$ Mechanical Engineering Department, University Technology PETRONAS, 32610 Bandar Seri \\ Iskandar, Malaysia. \\ ${ }^{2}$ PETRONAS Upstream, Level 48, PETRONAS Tower 3, Kuala Lumpur City Centre, 50088 Kuala \\ Lumpur, Malaysia \\ ${ }^{3}$ PETRONAS Carigali Sdn. Bhd., Peninsular Malaysia Operations, Kompleks Operasi Petronas, \\ 24300 Kertih, Kemaman, Terengganu, Malaysia
}

\begin{abstract}
Microstructural changes on a Nickel based superalloy service exposed gas turbine blade after 52,000 hours at $720^{\circ} \mathrm{C}$ temperature was investigated. The study examines the grain boundary growth sizes; the changes with respect to gamma prime ( $\gamma \mathrm{i})$ precipitate and phase distributions that occurred during operation. In order to observe the changes some different portions of the turbine blade undergone scanning electron microscope (SEM) to determine the grain size measurement and the EDX was used to evaluate the elemental analysis. The grain growths were discrete in formation along the grain boundary (GB) and little difference in the size of $\left(\gamma^{\prime}\right)$ precipitates existed in different locations. The gradual transition of grain boundary-carbide morphology from the original fine discrete to fine semi-continuous, continuous film-like and finally coarse is observed in the specimens. The changes mostly evolves around two distinct phases which is from the solid to the equilibrium (sigma coarse phase) and then back to the solid (hardening gamma prime precipitate) phase. The grain size of ( $\gamma \mathrm{i})$ precipitate varies throughout the surface of the turbine blade and there is a significant difference between the leading and trailing edge. The microstructural changes on the serviced blade can be interpreted to indicate that no obvious microstructural degradation and phase deformation occurred during exposure time
\end{abstract}

\section{Introduction}

Turbine blades are manufactured using super-alloys mostly due to their ability to withstand very high temperature and pressure and still retain most of their strength [1]. The turbine blades when subjected to stresses affect and bring about changes in their metallographic and morphological constituents, particularly the grain formation and microstructure. The changes in the microstructure can lead to degradation in the mechanical, and thermochemical

* Corresponding author: puteris@utp.edu.my 
properties such as tensile strength, creep resistance, resistivity and others [2]. The commonly used super-alloy is titanium, steel and nickel which are common to fabricate gas turbine blades. The alloys have different grain size and microstructure thus having different outcome and cause of failure. This is because microstructure plays a significant role in influencing the performance and lifespan of the gas turbine blade [3, 4]. Since the blades are prone to tough environment (high heat and pressure), turbine blades are normally limiting component in a gas turbine which requires consistence inspection to avoid failure unexpectedly [5]. Figure 1 show the turbine blade located at the hot section side of a turbine, right after the combustion.

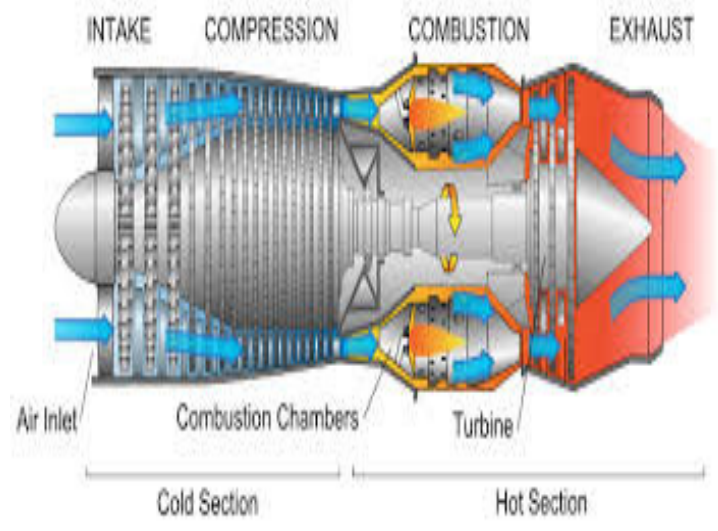

Fig. 1. Gas Turbine Sections [6].

Materials properties such as ductility, strength, toughness, density are also influenced by the microstructure. The microstructural transformation contains different phase transition, the phase can become a stable phase at the time scale the dynamic resistance is significance in respect to the varying large number of intermetallic alloys. The phase transformation during heat exposure to a Nickel based superalloy originates from phase -separated microstructures strengthened by coherent gamma prime $\left(\gamma^{i}\right)$ precipitate particles [6]. Depending on the dominant elemental composition, the intermediate product in the process of an equilibrium phase transition can be a pre-precipitated phase from a supersaturated solid solution at a certain temperature, rather than the final equilibrium phase temperature. Also, the stable phase, under certain diffusion time may transform to transition phase and vice versa. Microstructure containing finely dispersed gamma prime precipitate $\left(\gamma^{\mathrm{i}}\right)$ particles can be found in the coarse grain boundary region during heat exposure [7]. In the present study, the transformation in grain growth formation along the gamma prime ( $\gamma \mathrm{i})$ precipitate and the elemental composition at various regions of the turbine blade in an elastically constrained $\mathrm{Ni}$ alloy was investigated by means of transmission electron microscopy (SEM) and the EDX.

\section{Material Preparation}

To study the microstructural changes in the IN 738 turbine blade various specimens were cut from the outside wall and inside wall of the blade. The lower surface side of the aerofoil (near the outside wall) the middle and the upper (near the inside wall) sections of the aerofoil were also investigated. The images of the turbine blade displaying the suction and pressure side region of the blade are presented in Figure 2. 

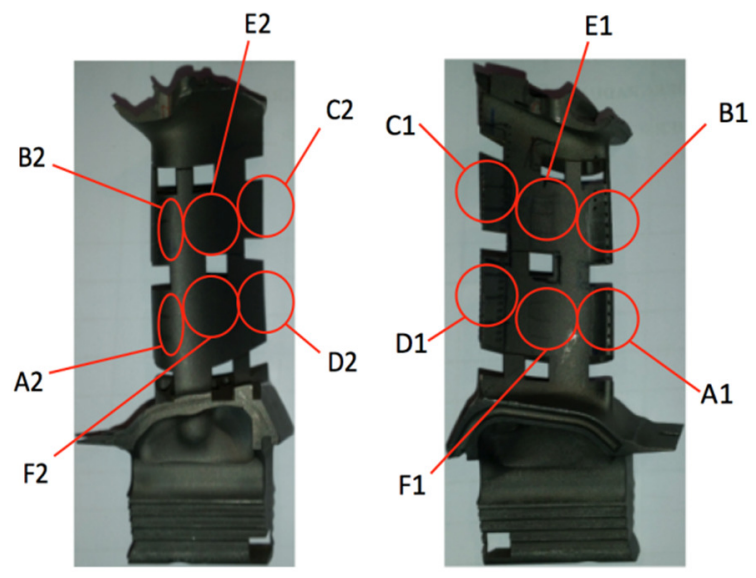

Fig. 2. (a) Suction Surface Side of Blade (b) Pressure Surface Side of Blade

Two samples from both the suction and pressure surface region were cut near to the leading edge as represented by A1, B1 and A2 and B2. Also the trailing edge samples from both surface region as represented by $\mathrm{C} 1, \mathrm{D} 1$ and $\mathrm{C} 2$ and D2. Another four samples were taken at the center of the blade for both suction $(\mathrm{E} 1, \mathrm{E} 2)$ and pressure surface $(\mathrm{F} 1, \mathrm{~F} 2)$ sides of the blade.

\subsection{Experimental Procedures}

The specimen cutting at various locations was carried out using an electric discharge machine (EDM), each sample was mounted using Buehler Simpliment 1000 automatic mounting press followed by standard grinding and polishing process until a flat and mirror image surface were obtained. Similar procedures have been used in literatures $[8,9]$. Both processes were done manually using Buehler Metaserv 2000 machine. The micrograph of the cut out samples at both the suction (A1) and pressure (A2) surface side is displayed in Figure 3 and 4.

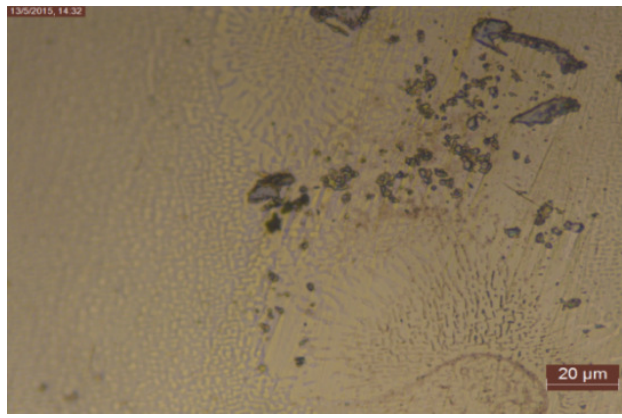

(a)

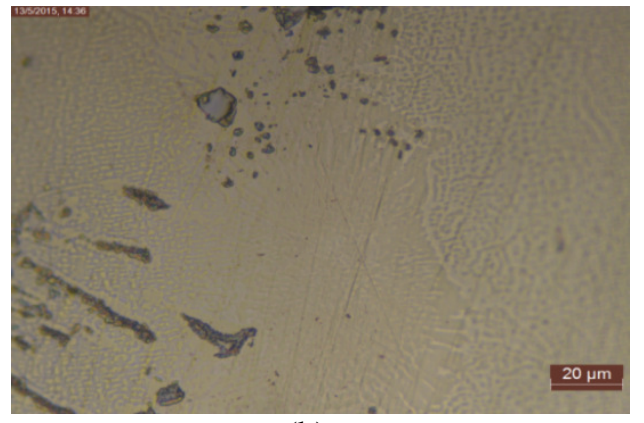

(b)

Fig. 3. (a) The micrograph of the suction surface side of blade at location A1, and (b) The micrograph of the pressure surface side of blade at location A2

For microstructural study, the microstructure of samples was investigated by optical emission spectroscopy before etching. The samples were then etched in a solution, and reinvestigated by optical microscopy, after which they were ground using Grit 240 up to 1,200 silicon carbide papers and polished with $6 \mu \mathrm{m}$ followed by $1 \mu \mathrm{m}$ alumina with distilled water as suspension solution on low napped polishing cloth. The elemental compositions are compared at different spots of the suction and pressure side surface samples at the lower, 
middle and upper region. The chemical composition of the investigated IN738 superalloy is shown in Table 1.

Table 1. Chemical composition of IN738 superalloy.

\begin{tabular}{|c|l|}
\hline Material & Composition (unit: wt. \%) \\
\hline & $0.11 \mathrm{C}, 15.084 \mathrm{Cr}, 8.5 \mathrm{Co}, 2.48 \mathrm{~W}, 1.88 \mathrm{Mo}$, \\
& $0.07 \mathrm{Fe}, 0.92 \mathrm{Nb}, 3.46 \mathrm{Al}, 3.47 \mathrm{Ti}, 1.69 \mathrm{Ta}$, \\
IN 738 & $0.001 \mathrm{~S}, 0.04 \mathrm{Zr}, 0.012 \mathrm{~B}$, balance Ni \\
\hline
\end{tabular}

The Energy-dispersive X-ray Spectroscopy (EDX) analysis was used to determine the elemental composition of each phase at various regions in the suction and pressure surface. The Figure $4 \mathrm{a}$ and $\mathrm{b}$ showed the elemental composition obtained at the two spot on suction and pressure side of the middle of the turbine blade specimen.

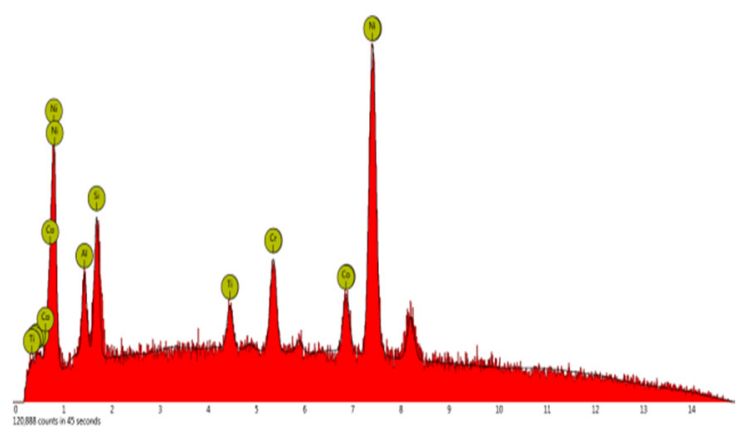

(a)

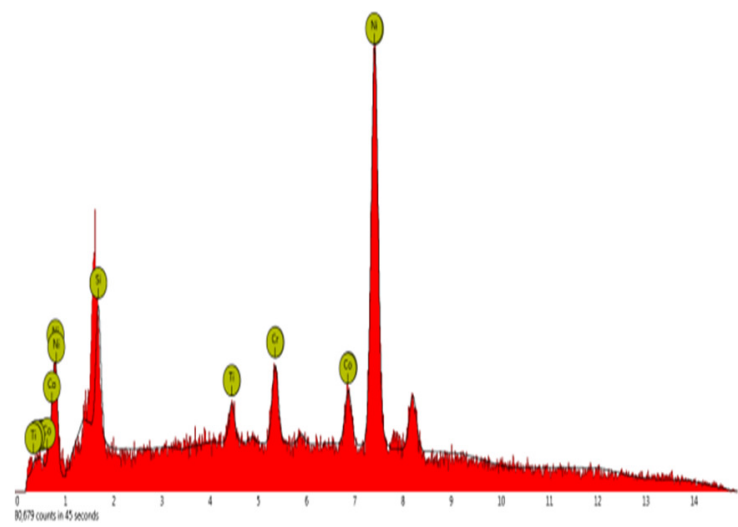

(b)

Fig. 4. (a) The elemental composition at suction surface side at spot A1 at the trailing edge, and (b) The elemental composition at pressure surface side at spot A2 at the trailing edge

The microstructural changes of the service-exposed blade were studied using a scanning electron microscopy (SEM). The surface was etched to reveal the microstructure. Grain size changes, morphology of carbides, and carbides decomposition or transformation. For this purpose, the metallographic specimens were electrolytic etched after polishing. The grain size, morphology of carbides, carbides decomposition or transformation, changes in the size and the morphology of gamma prime precipitate particles were all investigated. 


\section{Results and Discussion}

\subsection{Microstructure in the suction surface side of the sample (spot A1).}

The SEM image of the grain boundary development is shown in different magnification in Figure 5a-c. During thermal exposure, the matrix change elements within the primary MC carbides thereby increasing the thickening of the $\gamma^{\mathrm{i}}$ film along the grain boundary. The secondary $\gamma^{\mathrm{i}}$ particles coarsen and coalesce continuously, with a mean diameter of $350 \mathrm{~nm}$ according to the measurement carried out using the image $\mathbf{J}$ software. Spectrum in Figure 5a shows that Tantalum is at the highest peak.

The continued thickening in the grain boundary development can be as result of the aggressively mixing of the matrix elemental composition, the discrete $\mathrm{M}_{23} \mathrm{C} 6$ carbides particles grow much larger and coalesce into a continuous chain which is consonant with the report of [10]. The Figure 5c shows clearly the $\gamma^{\mathrm{i}}$ formation in liquid and equilibrium phase. The cobalt (Co) element diffuses into the matrix as well and the high Ti/Ta ratio further contributes to the grain growth although in a discrete order. During equilibrium $(\sigma)$ phase transition, the nucleating is intense at this point and the $\mathrm{C}$ atoms are trapped from the remaining $\mathrm{MC}$ and released to the remaining $\mathrm{MC}$ to form the $\mathrm{M}_{6} \mathrm{C}$ phase. The spot $\mathrm{A} 1$ is believed to be Cobalt-based carbide. This is because there is the presence of Carbon. Tantalum has recorded the highest concentration at this spot with $45.1 \%$. Besides that, the concentration of Nickel is very low with $2.7 \%$ only. This clearly proves that the white aligned structure is carbide.

In the report of [10] et al. the elemental constituents determines the phase pattern during transition. More so the declination can be due to microstructural alteration during the creep process which in turns reduces the strength of grain boundary matrix. Among the changes are the diminishing of serrated grain boundaries and coarsening of gamma prime $\gamma^{\mathrm{i}}$ phase. This change can leads to deterioration of mechanical properties and reduces the rupture time.
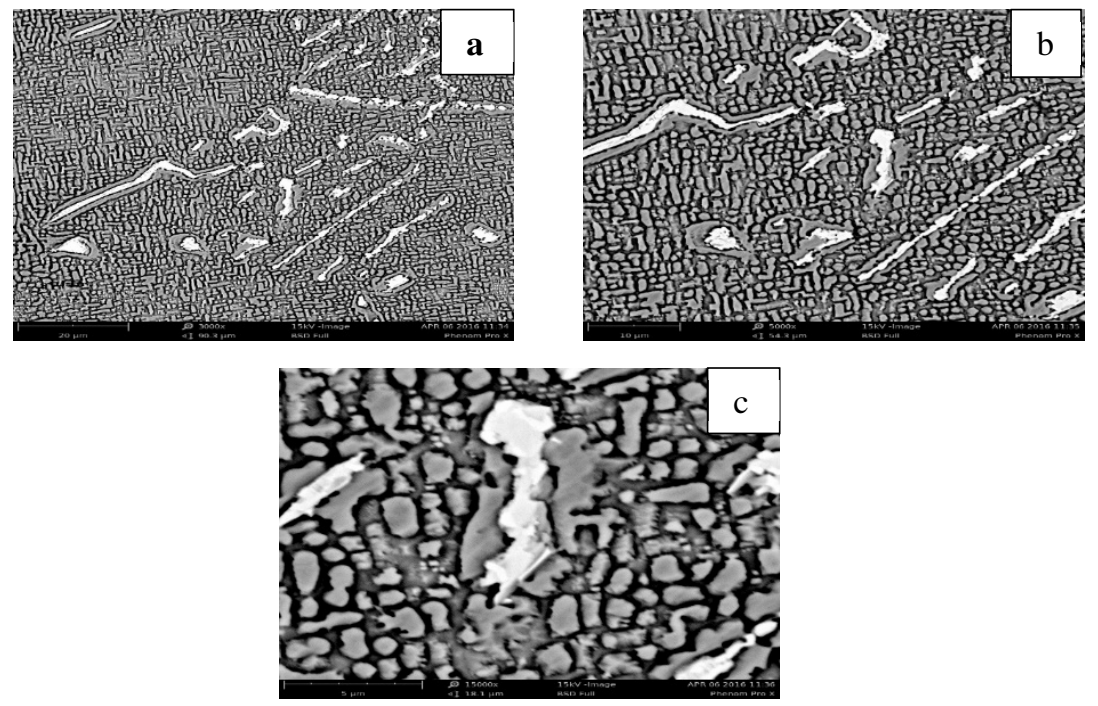

Fig. 5. Typical grain boundary carbide morphologies in spot A1 of the suction surface side of the turbine blade at different magnifications of (a) 20, (b) 10 , and (c) $5 \mu \mathrm{m}$. 


\subsection{Microstructure in the pressure surface side of the sample (spot A2).}

The Figure 6a-c shows the SEM image take at spot A2 at different magnifications. The MC carbides formation is discrete; the secondary grain growth appears along $\gamma \mathrm{i}$ precipitate in the hardened phase. The dominant carbides detected are the $\mathrm{MC}$ and $\mathrm{M}_{23} \mathrm{C}_{6}$ which form weak bonded matrix. The MC decomposition increases during transition from the hardened phase to the equilibrium phase. The primary carbides become much brighter under higher magnification. Further observation by EDX detects a coarse primary gamma prime precipitate. This is because the grain size has elongated and formed an awkward shape from the spectrum. Earlier described in Figure 4a and b, the highest peak is Nickel. This justify that the phase at spot A2 is gamma prime precipitate and this can contributes to the rapid formation of coarsening along the grain boundary.
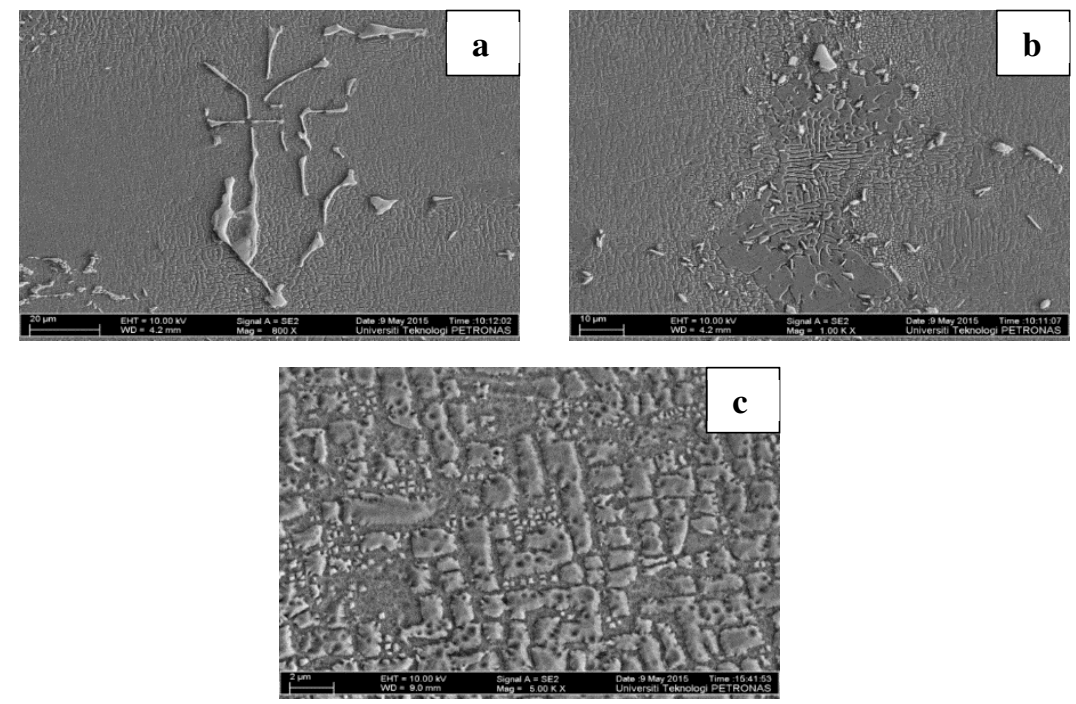

Fig. 6. Typical grain boundary carbide morphologies on pressure surface side of the turbine blade at in spot A2 at different magnifications of (a) 20, (b) 10 and (c) $5 \mu \mathrm{m}$.

\section{Conclusion}

Microstructural transformation in the serviced expose turbine blade manufactured from $\mathrm{Ni}$ superalloy was investigated after the service exposure for 52000 hours. The following deduction where made from the observation and findings:

1. The grain growth were discrete in formation and the GB carbides kept mainly fine discrete morphology; slight difference in the size of $\gamma^{\prime}$ precipitates existed in different locations, indicating the heat difference at both the suction surface and pressure surface sides of the blade.

2. The degradation in the GB formation can be traced to the elemental constituents in the samples tested. The alloy resulted in the gradual transition of GB carbide morphology from the original fine discrete to fine semi-continuous, continuous film-like and finally coarse discrete.

3. The combined results of microstructural evolution of the serviced blade can be interpreted to indicate that no obvious microstructural degradation and phase deformation occurred during exposure time. 
4. The specimen are observed to have grain growth formation right from the GB; the changes mostly evolves around two distinct phases which is from the solid to the equilibrium (sigma coarse phase) and then back to the solid (hardening gamma prime precipitate) phase.

The authors are grateful to university Teknologi PETRONAS for proving the financial and technical support to the study.

\section{Reference}

1. M. P. Boyce, Gas turbine engineering handbook: (Elsevier, 2011)

2. J. Tong, X. Ding, M. Wang, Y. Zheng, K. Yagi, and Q. Feng, Mater. Sci. Eng.: A, 618, pp. 605-613, (2014)

3. A. Epishin, T. Link, H. Klingelhöffer, B. Fedelich, and P. Portella, Mater. High temp., 27, pp. 53-59 (2014)

4. M. A. Skotnikova, N. A. Krylov, E. K. Ivanov, and G. V. Tsvetkova, Adv. Mech. Eng., pp. 159-168 (2016)

5. R. Woodason, An Experimental Investigation of the Influence of Service Exposure on the Aerodynamic Performance of Transonic Turbine Vanes (Royal Military College, Kingston, Canada, 2009).

6. R. Bowman, 9th International Symposium on Superalloys, 2000.

7. L. Zhuo, T. Xu, F. Wang, J. Xiong, and J. Zhu, Mater. Lett., 148, pp. 159-162, (2015)

8. J.-S. Chou, C.-K. Chiu, I.-K. Huang, and K.-N. Chi, Eng. Fail. Anal., 27, pp. 99118, (2013)

9. M. S. Siddiqui, P. Joshi, N. Nayak, and K. Vidyasagar, "Thermal spraying, optimization and characterization of abradable seal coating for gas turbine for service temperature up to 750 C," 2014.

10. Y. Zhou, H. Ye, and S. Rao, Metallogr. Microstruct. Anal. 5(4), pp. 321-326 (2016). 